\title{
Cleavage of ring $A$ and formation of an unusual nor-triterpene skeleton via the Baeyer-Villiger reaction
}

\author{
Özgür Tağ ${ }^{\mathrm{a}}$, Ali Çağır ${ }^{\mathrm{b}}$, Ikhlas A. Khan ${ }^{\mathrm{c}}$, Erdal Bedir ${ }^{\mathrm{d}, *}$ \\ a Department of Chemistry, Faculty of Science, Ege University, Bornova-Izmir, Turkey \\ ${ }^{\mathrm{b}}$ Department of Chemistry, Faculty of Science, Izmir Institute of Technology, 35430 Urla-Izmir, Turkey \\ ${ }^{\mathrm{c}}$ Department of Pharmacognosy, School of Pharmacy, The University of Mississippi, University, MS 38677, USA \\ ${ }^{\mathrm{d}}$ Department of Bioengineering, Faculty of Engineering, Ege University, 35100 Bornova-Izmir, Turkey
}

\section{A R T I C L E I N F O}

\section{Article history:}

Received 3 July 2012

Revised 1 August 2012

Accepted 16 August 2012

Available online 23 August 2012

\section{Keywords:}

Cycloastragenol

Semi-synthesis

Baeyer-Villiger

3,5-Seco-4-nor-triterpenes

\section{A B S T R A C T}

With the aim to generate a compound library for our biological screening studies, cycloastragenol was subjected to chemical transformation studies. The Baeyer-Villiger oxidation experiments provided an interesting 3,5-seco-4-nor-triterpene skeleton via ring opening followed by an unusual rearrangement. A new methodology is described for transforming triterpenoids into 3,5-seco-4-nor derivatives.

(c) 2012 Elsevier Ltd. All rights reserved.
Saponins have been given attention due to their bioactivities, and have become one of the primary targets for new pharmacologically active antitumor molecules.

Cellular screening of various semi-synthetic triterpenoid compounds formally derived from lupane, the aglycone of a well-known anti-cancer agent betulinic acid (BA), has identified a number of analogues as potential anti-cancer drug candidates. ${ }^{1,2}$ It is also worth mentioning that BA itself, as well as some of its derivatives, have been described as potent anti-HIV agents. ${ }^{3}$ A recent study revealed that a semi-synthetic oleanane-type saponin, 2-cyano-3,12-dioxoolean-1,9-dien-28-oic acid (CDDO) is a multi-functional molecule with promising clinical potential as a chemo-preventive agent and as a therapeutic agent for the treatment of cancer. ${ }^{4,5}$ In vitro studies have shown that CDDO induces cell differentiation, growth inhibition, and apoptosis in human leukemia, ${ }^{6,7}$ osteosarcoma, ${ }^{6}$ and breast cancer ${ }^{8}$ cell lines. As a result, lupane derivatives and CDDO are currently undergoing clinical trials.

Semi-synthetic anti-cancer drug-discovery programs focusing on saponins have mainly engaged with commercially available triterpenoids such as oleanolic acid and ursolic acid, less common miscellaneous aglycones such as cycloartanes, lanostanes, and hopanes have not been evaluated for their potentials.

The cycloartanes, which are unique triterpenoids with a characteristic 9,19-cyclopropane ring, occupy a special position among low molecular weight bioregulators since cycloartenol is a key

\footnotetext{
* Corresponding author. Tel./fax: +90 232388495532.

E-mail address: erdalbedir@gmail.com (E. Bedir).
}

intermediate in the biosynthesis of different phytosterols. ${ }^{9}$ For this reason, cycloartenol and its weakly polar derivatives are widespread in the plant kingdom. The plants of the Astragalus genera are the richest source of this class of compounds. The main sapogenol of many cycloartane-type glycosides found in this genus is cycloastragenol $\quad(C A), \quad 20(R), 24(S)$-epoxy-3 $3,6 \alpha, 16 \beta, 25$ tetrahydroxycycloartane.

However, studies on the preparation of CA analogues have so far been limited. ${ }^{10-12}$ In continuation of our studies on the chemistry and biological activities of Astragalus cycloartanes, ${ }^{13-16}$ we have directed our efforts toward the exploration of various analogues of CA to generate a library of structurally similar compounds for cytotoxicity screening studies.

Herein, we report an unusual modification of ring A of CA by utilizing the Baeyer-Villiger (BV) oxidation.

Following on from our research into the transformations of cycloastragenol (1), we first aimed to obtain astragenol (AG), which is the main artifact of the acidic hydrolysis process of CA production from the glycosidic precursors, and subsequently other derivatives (Fig. 1).

Acid-catalyzed cyclopropane ring-opening of CA yielded astragenol (AG) (2) as a white solid in $65 \%$ yield. ${ }^{17}$ The structure of the semi-synthetic product was characterized by HRESIMS and NMR analyses. The structure of hydrolyzed product AG was readily deduced based on the following observations: (i) the disappearance of the characteristic 9,19-cyclopropane protons; (ii) the observation of the extra methyl group at $\delta 1.14\left(\mathrm{H}_{3}-19\right)$ and $\delta 23.4$ (C19); (iii) the appearance of a trisubstituted olefinic system due to 


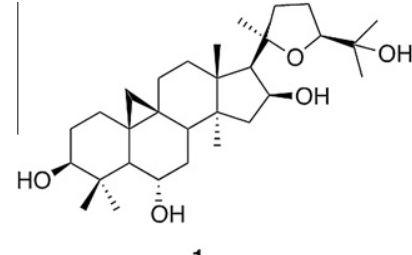

1

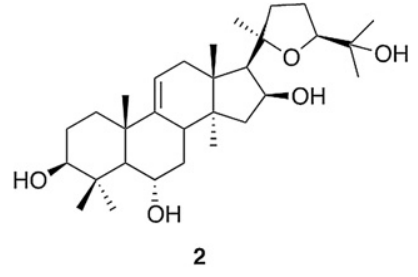

Figure 1. Structures of cycloastragenol (1) and astragenol (2).

the $\Delta^{9(11)}$ double bond $\left(\delta_{\mathrm{H}} 5.27 ; \delta_{\mathrm{C}} 146.6\right.$ and 115.6) in the ${ }^{1} \mathrm{H}$ and ${ }^{13} \mathrm{C}$ NMR spectra. ${ }^{18}$

After obtaining AG, the oxidation of the secondary alcohols into carbonyl groups was undertaken. For this transformation, high-valent metal oxides or their mineral salts are the reagents of choice, amongst which the Jones reagent is the best known $\mathrm{Cr}(\mathrm{VI})$ reagent for the oxidation of secondary alcohols to ketones. ${ }^{19}$

When we subjected compound $\mathbf{2}$ to Jones oxidation conditions, compound $\mathbf{3}$ or $\mathbf{4}$ was isolated as the major product depending on the reaction temperature (Fig. 2). ${ }^{20}$ At $0{ }^{\circ} \mathrm{C}$, Jones oxidation resulted in $\mathbf{3}$ in $64 \%$ yield as a white powder. When compared to $\mathbf{2}$, the absence of low-field oxymethine signals due to $\mathrm{H}-3, \mathrm{H}-6$, and $\mathrm{H}-16$ in the ${ }^{1} \mathrm{H}$ NMR, and the observation of three carbonyl carbons $(213.7,209.6,214.6)$ instead of the corresponding oxymethine carbons in the ${ }^{13} \mathrm{C}$ NMR spectrum confirmed the formation of compound 3. The accurate mass measurement also substantiated these findings (HRESIMS: $m / z \quad 507.3115 \quad[\mathrm{M}+\mathrm{Na}]^{+}$; Calcd: 484.3189 for $\mathrm{C}_{30} \mathrm{H}_{44} \mathrm{O}_{5}$ ).

On the other hand, when the oxidation was performed at room temperature, an alternative major product $(4,72 \%$ yield) was observed. The HRESIMS spectrum of $\mathbf{4}$ showed a major ion at $\mathrm{m} / \mathrm{z}$ 458.2924 which was assigned to $\left[\mathrm{M}+\mathrm{NH}_{4}\right]^{+}$. Together with the ${ }^{13} \mathrm{C}$ NMR data, accurate mass data supported a molecular formula of $\mathrm{C}_{27} \mathrm{H}_{36} \mathrm{O}_{5}$ (Calcd: 440.2563). The NMR spectra of $\mathbf{3}$ and $\mathbf{4}$ were identical except the 20,24-lactone ring. The $\mathrm{C}-25(0)$ resonance and its attached methyl groups (Me-26 and Me-27) were missing in the ${ }^{1} \mathrm{H}$ and ${ }^{13} \mathrm{C}$ NMR spectra of $\mathbf{4}$, whereas two low-field carbon signals at $\delta 86.9$ and 176.3 were attributed to C-20 and C-24, 'respectively', indicating a 20,24-olide ring system ( $\gamma$-lactone). The $\gamma$-butyrolactones of acylated CA and its glycosides were previously prepared by Isaev et al. via Jones oxidation to afford more potent cardiotonic agents. ${ }^{11}$ A comparison of the spectral data of $\mathbf{4}$ and the reported analogues confirmed the elucidated 25-nor structure.

The Baeyer-Villiger oxidation is generally a reliable process for the conversion of cyclic and acyclic ketones into lactones and esters, 'respectively'. ${ }^{21} \mathrm{BV}$ oxidations are also of great importance for the field of natural products to obtain interesting products via stereo- and regioselective reactions. ${ }^{22-24}$ Particularly on the basis of its great success in synthetic steroid chemistry toward bioactive agents, we utilized the BV oxidation on the 25-nor-AG (4) as a key step to afford lactones and seco-cycloartane building blocks via subsequent ring-opening.

When compound $\mathbf{4}$ was subjected to BV oxidation using an excess of $m$-CPBA ( 5 equiv), a white crystalline solid (5) was obtained as the major product after purification. ${ }^{25}$ The IR spectrum of $\mathbf{5}$ indi-
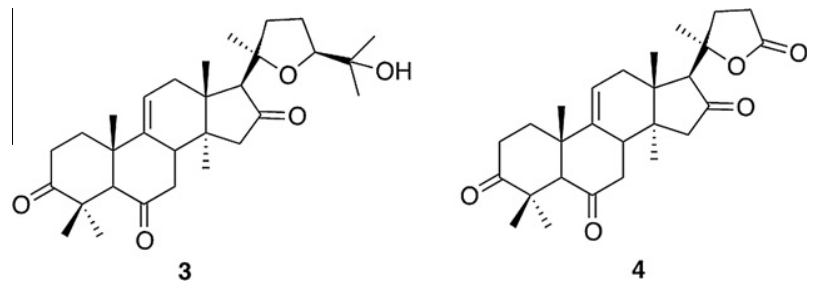

Figure 2. Structures of oxidation products $\mathbf{3}$ and $\mathbf{4}$. cated the presence of hydroxy $\left(3406 \mathrm{~cm}^{-1}\right)$ and carbonyl (1730, $1710,1769 \mathrm{~cm}^{-1}$ ) functional groups. The HRESIMS of 5 provided $[\mathrm{M}+\mathrm{H}]^{+}$at $\mathrm{m} / \mathrm{z} 461.2549\left[^{(+)}\right.$mode] and $[\mathrm{M}+\mathrm{Cl}]^{-}$at $\mathrm{m} / \mathrm{z} 495.1696$ $\left[(-)\right.$ mode] implying the molecular formula $\mathrm{C}_{26} \mathrm{H}_{36} \mathrm{O}_{7}$.

To our surprise, inspection of the ${ }^{1} \mathrm{H}$ NMR spectrum of $\mathbf{5}$ showed noteworthy discrepancies compared to starting molecule 4. Firstly, instead of five tertiary methyls, a primary $(\delta 1.16, \mathrm{t}, 6.8 \mathrm{~Hz})$ and four tertiary methyl groups $(\delta 1.04,1.07,1.11,1.47$, each s) were observed together with two low-field signals at $\delta 4.15$ (q, $J=6.8 \mathrm{~Hz})$ and $3.36(\mathrm{~d}, J=6.0 \mathrm{~Hz})$. Second, the absence of $\Delta^{9(11)}$ olefinic protons was apparent from the ${ }^{1} \mathrm{H}$ NMR spectrum. The ${ }^{13} \mathrm{C}$ and DEPT spectra showed that the resonances assigned to the product comprised 5 methyl, 9 methylene, 3 methine, and 9 quaternary carbons, four of which were carbonyl carbons as ester/lactone $(\delta$ 174.5 and 177.3 ) or ketone carbons ( $\delta 209.6$ and 215.9) (Table 1$)$.

The characteristic signals of the 20,24-olide (ring-E) and ring-D $[C(13) \rightarrow C(17)]$ in compound $\mathbf{5}$ were readily deduced from the proton and carbon chemical shifts (Table 1). Taking into account the results of comprehensive 1D- and 2D NMR studies, and the previously reported spectroscopic data of related isolated metabolites, it was inferred that $\mathbf{5}$ had a seco-structure with missing carbons.

The combined use of DQF-COSY and HMQC spectra, allowed the assignment of five spin systems (Fig. 3) excluding the signals ascribable to the 20,24-olide and the E-ring: ' $\mathrm{A}$ ' $\left(\mathrm{H}_{2}-1 \rightarrow \mathrm{H}_{2}-2\right)$, ' $\mathrm{B}$ ' (ethanoyl) and ' $\mathrm{C}$ ' $\left(\mathrm{H}_{2}-5\right)$, 'D' $\left(\mathrm{H}_{2}-7 \rightarrow \mathrm{H}-8\right)$ and 'E' (H-11 $\left.\rightarrow \mathrm{H}_{2}-12\right)$.

The $\delta 1.52$ and 1.91 signals, corresponding with a methylene carbon at $\delta 30.9$ in the HMQC spectrum, coupled with another methylene system at $\delta 2.34$ and $2.70\left(\delta_{\mathrm{C}} 30.2\right)$ ('A'). The spin system B started with the primary methyl resonance $(\delta 1.16, \mathrm{t}$, $J=6.8 \mathrm{~Hz}$ ), which showed a cross peak with a quartet signal at $\delta 4.15(\mathrm{~J}=6.8 \mathrm{~Hz})$, suggesting an ethanoyl unit. These two spin systems (A and B) were connected to each other based on the long-range correlations from an ester carbonyl $(\delta 174.5)$ to the primary alcohol proton $(\delta 4.15)$ and $\mathrm{H}_{2}-1$, in the HMBC spectrum. The low-field proton at $\delta 3.36(\mathrm{~d}, J=6.0 \mathrm{~Hz})$ showed a cross peak with the $\delta 2.12$ signal (dd, $J=14.8$ and $5.7 \mathrm{~Hz}$ ), while the latter coupled with a resonance at $2.22 \mathrm{ppm}(\mathrm{d}, J=14.8)$ ('E').

Table 1

${ }^{13} \mathrm{C}$ and ${ }^{1} \mathrm{H}$ NMR data of 5 recorded in pyridine $d_{5}(100 \mathrm{MHz}$ and $400 \mathrm{MHz}$, respectively) $)^{\mathrm{a}}$

\begin{tabular}{lll}
\hline $\mathrm{C} / \mathrm{H}$ & $\delta_{\mathrm{C}}(\mathbf{5})(\mathrm{ppm})$ & $\delta_{\mathrm{H}}(\mathbf{5})(\mathrm{ppm}), J(\mathrm{~Hz})$ \\
\hline 1 & 30.9 & $1.52^{\mathrm{b}}, 1.91^{\mathrm{b}}$ \\
2 & 30.2 & $2.34^{\mathrm{b}}, 2.70^{\mathrm{b}}$ \\
3 & 174.5 & \\
5 & 50.8 & $2.30^{\mathrm{b}}, 2.59(\mathrm{~d}, 13.3)$ \\
6 & 209.6 & \\
7 & 43.0 & $2.25^{\mathrm{b}}, 2.70^{\mathrm{b}}$ \\
8 & 38.9 & $2.68^{\mathrm{b}}$ \\
9 & 66.5 & \\
10 & 41.6 & \\
11 & 55.8 & $3.36(\mathrm{~d}, 5.6)$ \\
12 & 34.0 & $2.12(\mathrm{dd}, 14.8,5.7), 2.22(\mathrm{~d}, 14.4)$ \\
13 & 45.9 & \\
14 & 41.9 & $1.95(\mathrm{~d}, 17.8), 2.22(\mathrm{~d}, 18.0)$ \\
15 & 50.9 & \\
16 & 215.9 & $3.07 \mathrm{~s}$ \\
17 & 64.5 & $1.04 \mathrm{~s}$ \\
18 & 19.5 & $1.11 \mathrm{~s}$ \\
19 & 23.6 & $1.47 \mathrm{~s}$ \\
20 & 87.5 & $1.51^{\mathrm{b}}, 1.91^{\mathrm{b}}$ \\
21 & 27.2 & $2.34^{\mathrm{b}}, 2.66^{\mathrm{b}}$ \\
22 & 31.3 & $1.07 \mathrm{~s}$ \\
23 & 29.9 & $4.15 \mathrm{q}(6.8), 1.16 \mathrm{t}(7.2)$ \\
24 & 177.2 & \\
30 & 19.6 & \\
$0 \mathrm{Et}$ & $61.4,15.2$ & \\
& &
\end{tabular}

\footnotetext{
a Assignments confirmed by COSY, HMQC and HMBC experiments.
}

b Overlapping signals. 


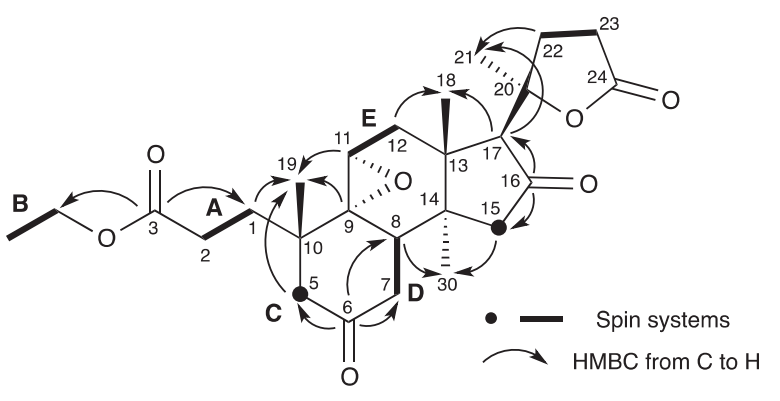

Figure 3. The spin systems (COSY) and key long-range correlations (HMBC) present in compound $\mathbf{5}$.

The HMQC spectrum revealed two carbons $(\delta 55.8 \rightarrow 3.36, \mathrm{H}-11$; $\delta 34.0 \rightarrow 2.12$ and $2.22, \mathrm{H}_{2}-12$ ) for the spin system $\mathrm{E}$. The carbon and proton chemical shifts of $\mathrm{C}(\mathrm{H})-11$ was indicative of an epoxy ring via oxidation of the $\Delta^{9(11)}$ double bond. Observation of the C-9 signal at $\delta 66.5$, and key long-range connectivities from C9 to $\mathrm{H}_{2}-12$ and $\mathrm{H}_{3}-19$, from $\mathrm{C}-11$ to $\mathrm{H}_{3}-19$, and from $\mathrm{C}-12$ to $\mathrm{H}_{3}-18$ not only helped in locating the spin system $\mathrm{E}$, but also connected the fragments.

In the DQF-COSY spectrum, an isolated spin system (' $\mathrm{C}$ ') due to two methylene protons was observed at $\delta 2.30$ and 2.59 (d, $J=13.3 \mathrm{~Hz} ; \delta_{\mathrm{C}} 38.9$ from HMQC), whereas the signal at $\delta 2.68\left(\delta_{\mathrm{C}}\right.$ 38.9) displayed cross peaks with the $\delta 2.25$ and 2.70 methylene signals correlating with a carbon at $\delta 43.0$ ('D'). The low-field shifts of the methylene carbons and protons of the ' $C$ ' and ' $D$ ' spin systems were significant for their adjacent position to a ketone carbon. Accordingly, the ketone carbon at $\delta 209.6$ displayed long-range correlations to the protons of the ' $C$ ' and ' $D$ ' spin systems, whereas the $\delta 50.9$ signal showed connectivity with $\mathrm{H}_{3}-19$ allowing it to be assigned unambiguously to C-5.

Additionally, the $\mathrm{C}-8\left(\delta\right.$ 38.9) and $\mathrm{H}_{3}-30(\delta$ 1.07) correlation in the HMBC spectrum revealed the location of the spin system ' $D$ ' in the B-ring. In a similar fashion, the quaternary carbon signals of $\mathrm{C}-10, \mathrm{C}-13$, and $\mathrm{C}-14$ were readily assigned on the basis of long-range connectivities to $\mathrm{H}_{3}-19, \mathrm{H}_{3}-18$, and $\mathrm{H}_{3}-30$, 'respectively'.

The relative stereochemistry of the new chiral center at C-11 was assigned by a combination of coupling constant analysis and molecular modeling studies performed on $\mathbf{5}$. The minimum energy conformations of $\alpha$ - and $\beta$-oriented epoxy rings were calculated with a 3-D computer-generated model. Since the $\mathrm{H}-11$ resonance was observed as a doublet with a $6.0 \mathrm{~Hz}$ coupling constant $(\delta$ 3.36), it must be equatorial, while the dihedral angle between $\mathrm{H}$ 11 equiv and $\mathrm{H}-12 \mathrm{ax}$ is required to be about $90^{\circ}$. Only in the case of an $\alpha$-oriented epoxy ring is this dihedral angle possible, ruling out the $\beta$-orientation of the epoxy ring.

Consequently, a 4,25,26,27,28,29-hexanor framework was established based on the spectral data, and a mechanistic sequence for compound $\mathbf{5}$ is shown in Scheme 1.

BV oxidation of $\mathbf{4}$ can yield esters $\mathbf{5}$ and $\mathbf{1 0}$ depending on the added alcohol in the work-up steps. Although the formation of $\mathbf{6}$ was expected from BV oxidation of $\mathbf{4}$, the carbonyls can be further protonated by excess $m$-chloroperbenzoic acid as shown in structure 6. After the addition of an alcohol, an equilibrium will be formed between compounds $\mathbf{6}$ and 7. This equilibrium can be disturbed toward the formation of an enol product $\mathbf{8}$ by a retro-aldol reaction with elimination of acetone. Enol 8 rearranges into its keto form $\mathbf{9}$ in alcoholic solution. So the addition of ethanol or methanol in the work-up step yields the corresponding ethyl $\mathbf{5}$ or methyl $\mathbf{1 0}$ esters.

In conclusion, Jones reaction, followed by ring cleavage through BV oxidation and an in situ retro-aldol reaction provided an unusual 3,5-seco-4,25,26,27,28,29-hexanor-triterpenoid framework. This skeleton was reported for the first time demonstrating the potential of the BV oxidation for the transformation of the steroidal/ triterpenoid nucleus. The structure activity relationships of these novel compounds including A-ring opened products will be evaluated for their biological potential and the results will be reported in due course.

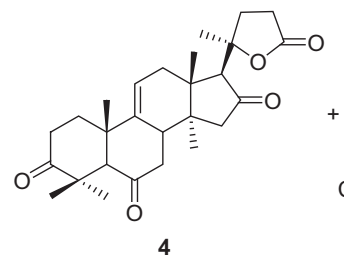<smiles>O=C(O)c1cccc(Cl)c1</smiles>

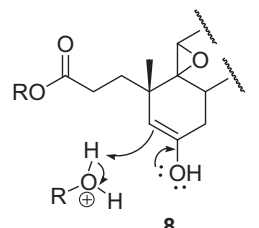<smiles>[R6]C(=O)CCC1(C)CC(=O)CC(C)C12OCCO2</smiles>

9

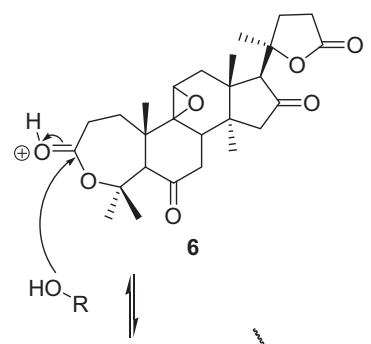<smiles>[CH-][CH-]</smiles>

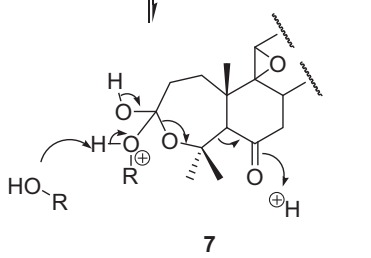<smiles>C1CC2C[I-]CC2C1</smiles> 


\section{Acknowledgements}

This work is supported by TUBITAK (109S345) and COST Action CM 0804. We are very grateful to Dr. Markus Ganzera and Dr. Bharathi Avula for their help in mass measurements. We also acknowledge partial support from the Global Research Network for Medicinal Plants (GRNMP) and King Saud University.

\section{Supplementary data}

Supplementary data (HR-MS spectra and 1D-NMR spectra of 3 and 4, HR-MS spectra, 1D-and 2D-NMR spectra of $\mathbf{5}$, and carbon NMR data of $\mathbf{3}$ and $\mathbf{4}$ ) associated with this article can be found, in the online version, at http://dx.doi.org/10.1016/ j.tetlet.2012.08.068.

\section{References and notes}

1. Sarek, J.; Urban, M.; Klinot, J.; Korinkova, G.; Hajduch, M. J. Nat. Prod. 2004, 67, 1100-1105.

2. Santos, R. C.; Salvador, J. A. R.; Marín, S.; Cascante, M. Bioorg. Med. Chem. Lett. 2009, 17, 6241-6250.

3. Mayaux, J. F.; Bousseau, A.; Pauwels, R.; Huet, T.; Henin, Y.; Dereu, N.; Evers, M. Proc. Natl. Acad. Sci. U.S.A. 1994, 91, 3564-3568.

4. Suh, N.; Yongping, W.; Tadashi, H.; Gordon, W. G.; Ethan, D.; William, F. H.; Robert, A. M. Cancer Res. 1999, 59, 336-341.

5. Koohang, A.; Majewski, D. N.; Szotek, E. L.; Mar, A. A.; Eiznhamer, D. A.; Flavin, M. T.; Xu, Z. Q. Bioorg. Med. Chem. Lett. 2009, 19, 2168-2171.

6. Ito, Y.; Pandey, P.; Sporn, M. B.; Datta, R.; Kharbanda, S.; Kufe, D. Mol Pharmacol. 2001, 59, 1094-1099.

7. Pedersen, I. M.; Shinichi, K.; Aaron, S.; Youngsoo, K.; Juan, M. Z.; Lula, C.; Laura, R.; Andreeff, M.; Bennett, F.; Sporn, M. B.; Liotta, L. D.; Kipps, T. J.; Reed, J. C. Blood 2002, 100, 2965-2972.

8. Lapillonne, H.; Konopleva, M.; Tsao, T.; Gold, D.; McQueen, T.; Madden, T.; Andreeff, M. Exp. Hematol. 2003, 31, 66-69.

9. Dewick, P. M. Medicinal Natural Products: A Biosynthetic Approach; Wiley, 2002.

10. Kuban, M.; Öngen, G.; Bedir, E. Org. Lett. 2010, 12, 4252-4255.

11. Isaev, I. M.; Iskenderov, D. A.; Isaev, M. I. Chem. Nat. Compd. 2009, 45, 381-384.

12. Yang, W.; Ye, M.; Huang, F.; He, W.; Guo, D. Adv. Synth. Catal. 2012, 354, 527 539.

13. Horro, I.; Bedir, E.; Perrone, A.; Özgökçe, F.; Piacente, S.; Çalışkan, Ö. A. Phytochemistry 2010, 71, 956-963.
14. Gülcemal, D.; Çalışkan, Ö. A.; Perrone, A.; Özgökçe, F.; Piacente, S.; Bedir, E. Phytochemistry 2011, 72, 761-768.

15. Nalbantsoy, A.; Nesil, T.; Erden, S.; Çalış, İ.; Bedir, E. J. Ethnopharmacol. 2011, 134, 897-903.

16. Gür, C. S.; Onbaşılar, İ; Atilla, P.; Genç, R.; Çakar, N.; Gürhan, İ. D.; Bedir, E. J. Ethnopharmacol. 2011, 134, 844-850.

17. A solution of CA (1) $(1.0 \mathrm{~g}, 2.28 \mathrm{mmol})$ in $\mathrm{MeOH}(50 \mathrm{~mL})$ was treated with concd $\mathrm{H}_{2} \mathrm{SO}_{4}(5 \mathrm{~mL})$ and the mixture was heated under reflux for $6 \mathrm{~h}$. The reaction mixture was poured into $\mathrm{H}_{2} \mathrm{O}(50 \mathrm{~mL})$ and extracted with EtOAc $(2 \times 50 \mathrm{~mL})$. The EtOAc extract was washed successively with aq satd $\mathrm{NaHCO}_{3}$ and $\mathrm{H}_{2} \mathrm{O}$, dried over $\mathrm{Na}_{2} \mathrm{SO}_{4}$ and filtered. The filtrate was evaporated, and chromatographic separation of the crude product on a silica gel column was performed using hexanes:EtOAc (6:4) as eluent to give AG (2) as a white solid (65\% yield).

18. Kitagawa, I.; Wang, K. H.; Takagi, A.; Fuchida, M.; Miura, I.; Yoshikawa, M. Chem. Pharm. Bull. 1983, 31, 689-697.

19. Cainelli, G.; Cardillo, G. Chromium Oxidations in Organic Chemistry; SpringerVerlag: Berlin, 1984.

20. To a stirred mixture of $\mathbf{2}(500 \mathrm{mg}, 1.14 \mathrm{mmol})$ in acetone $(150 \mathrm{~mL})$, Jones reagent $(0.4 \mathrm{~mL}, 3.3 \mathrm{mmol})$ was added slowly at $0{ }^{\circ} \mathrm{C}$ to furnish major compound 3 as a white solid (64\% yield). Freshly prepared Jones reagent $\left(\mathrm{CrO}_{3}, 3 \mathrm{~g}\right.$ : distilled $\mathrm{H}_{2} \mathrm{O}, 9 \mathrm{~mL}$ and concd $\left.\mathrm{H}_{2} \mathrm{SO}_{4}, 1.5 \mathrm{~mL}\right)$ was added to a solution of $2(500 \mathrm{mg}, 1.14 \mathrm{mmol})$ in acetone and stirred at room temperature until completion of the reaction. After adding satd aq $\mathrm{NaHCO}_{3}(25 \mathrm{~mL})$, the aqueous mixture was extracted with $\mathrm{CH}_{2} \mathrm{Cl}_{2}(3 \times 25 \mathrm{~mL})$. The combined organic layers were washed with brine solution $(25 \mathrm{~mL})$, dried over $\mathrm{Na}_{2} \mathrm{SO}_{4}$ and filtered. The filtrate was evaporated, and chromatographic separation of the crude product on a silica gel column was performed by using hexanes:EtOAc (8:2) as eluent to give 4 as a white solid (72\% yield); mp 204-206 ${ }^{\circ} \mathrm{C} ;[\alpha]_{\mathrm{D}}^{23}-57.9($ c $0.005, \mathrm{MeOH})$.

21. Baeyer, A.; Villiger, V. Ber. 1900, 33, 858-864.

22. Harmata, M.; Rashatasakhon, P. Tetrahedron Lett. 2002, 43, 3641

23. Rivera, D. G.; Pando, O.; Suardiaz, R.; Coll, F. Steroids 2007, 72, 466-473.

24. ten Brink, G. J.; Arends, I. W. C. E.; Sheldon, R. A. Chem. Rev. 2004, 104, 41054123.

25. To a stirred solution of 4 (200 $\mathrm{mg}, 0.454 \mathrm{mmol})$ in $\mathrm{CHCl}_{3}(8 \mathrm{~mL}), 5$ equiv of $\mathrm{m}$ CPBA $(0.509 \mathrm{~g}, 2.27 \mathrm{mmol}$ ) were added portionwise at room temperature. The mixture was refluxed with stirring for $8 \mathrm{~h}$. The mixture was allowed to cool to room temperature followed by evaporation in vacuo. The residue was dissolved in a minimum amount of $\mathrm{EtOH}$, and then saturated $\mathrm{NaHCO}_{3}$ $(25 \mathrm{~mL})$ solution was added, followed by EtOAc extraction $(3 \times 25 \mathrm{~mL})$. The combined organic layers were washed with $\mathrm{H}_{2} \mathrm{O}(3 \times 25 \mathrm{~mL})$, brine $(3 \times 25 \mathrm{~mL})$, dried over anhyd $\mathrm{Na}_{2} \mathrm{SO}_{4}$ and filtered. The resulting filtrate was evaporated in vacuo to give a solid. The solid residue was subjected to column chromatography [hexanes-EtOAc ( $7: 3)$ ] to give 5 as a crystalline solid (128 mg, $64 \%$ yield); mp $146-149^{\circ} \mathrm{C} ;[\alpha]_{\mathrm{D}}^{23}-62.3($ c $0.005, \mathrm{MeOH})$. 